\title{
Anisotropic Elastoplastic and Damage Behavior of SiCp/Al Composite Sheets
}

\author{
D. A. Skolnik \\ Department of Civil and Environmental Engineering \\ University of California, Los Angeles, CA 90095-1593
}

H. T. LIU

American Bureau of Shipping, ABS Plaza, Houston, TX 77060

\author{
H. C. $\mathrm{Wu}$ \\ Department of Civil and Environmental Engineering \\ The University of Iowa, Iowa City, IA 52242-1527 \\ L. Z. SuN* \\ Department of Civil and Environmental Engineering \\ University of California, Irvine, CA 92697-2175
}

\begin{abstract}
A combined experimental and modeling research is performed to study the anisotropic elastoplastic and damage responses of $\mathrm{SiC}$ particle-reinforced Al composite sheets. To investigate the effects of the composite processing, two sets of specimens cut from the heat-treated and as-rolled composite sheets are tested under uniaxial loading. The dependence of the strength, plastic flow, and strain ratios on the rolling angles are discussed in detail. To model the phenomena observed in the experiments, a micromechanics-based damage framework is further developed. The interfacial debonding and the rolling angle's effects are integrated into this model. Good consistency between the experimental results and the analytical predications demonstrates the validity of the theoretical model.
\end{abstract}

KEY WORDS: composite materials, metal matrix composite sheets, anisotropy, plasticity, strain ratio, micromechanics, damage mechanics, interfacial debonding.

*Author to whom correspondence should be addressed. E-mail: 1sun@uci.edu

International Journal of DAmage Mechanics, Vol. 17-May 2008 


\section{INTRODUCTION}

$\mathbf{P}$ ARTICLE-REINFORCED METAL-MATRIX COMPOSITE (PRMMC) sheets have great potential as structural materials for aerospace, automotive, thermal management, electronic, and recreational and infrastructure industries due to their high structural efficiency, excellent wear resistance, and attractive thermal and electrical characteristics (Miracle, 2005). However, the adolescent knowledge of the mechanical behavior of PRMMC sheets currently prohibits confident and widespread industrial application. Anisotropy coming from the fabrication process and their corresponding microstructure are important aspects among these properties that need to be further investigated for PRMMC sheets (Kourkoulis and Andrianopoulos, 2000; Kourkoulis, 2002; Prasad et al., 2002). Specifically, Lee and Subramanian (1992, 1995), Kanetake et al. (1997), and Euh and Kang (2005) investigated the effect of rolling process on the tensile properties of PRMMCs and indicted that rolling was associated with a considerable amount of damage to particles. Shamsul et al. (1998) carried out a study of the relation of texture, microstructure and anisotropic mechanical properties of $2124 \mathrm{Al} / \mathrm{SiCp}$ composites. Cavaliere (2005) conducted the effect of friction stir processing on tension and fatigue properties of $2618 \mathrm{Al} / \mathrm{Al}_{2} \mathrm{O}_{3}$ p sheets.

The present investigation is aimed at studying the combined anisotropic elastoplastic and damage responses of $\mathrm{SiCp} / \mathrm{Al}$ composite rolling sheets. Experimentally, specimens are cut at various angles to the rolling direction from PRMMC and matrix-only sheets with multiple thicknesses. Under uniaxial tension, composite and matrix-only stress-strain curves are determined by using a universal material testing machine. The dependence of the strength, plastic flow, and strain ratios on composite processing (heattreated or as-rolled) and orientation angles are discussed in detail. Furthermore, a micromechanics-based damage model is applied to simulate the anisotropic behavior of PRMMC sheets, with consideration of particle alignment and interfacial debonding due to the fabrication and the test processes. The comparison between the experimental and simulation results is made to demonstrate the elastoplastic deformation and microstructural damage mechanisms of PRMMC sheets.

\section{EXPERIMENTAL PROCEDURES}

\section{Materials}

The material of the present study's interest is a particle-reinforced metal matrix composite consisting of an aluminum-A359 matrix and SiC 
particulates obtained from MC-21, Inc. The matrix alloy-A359 is a material purposely developed by the manufacturer for use as a matrix alloy in PRMMCs. The composite and matrix-only material were obtained as several sheets of multiple thicknesses in an as-hot-rolled condition. The composite's fabrication involved an MC-21 proprietary powder metallurgical process in which $\mathrm{SiC}$ particles were stirred into molten aluminum. After complete dispersion, the molten was then cast into flat molds to produce rolling slabs approximately $1^{\prime \prime}$ thick. A conventional rolling mill hot rolled the slabs at a temperature of $750^{\circ} \mathrm{F}$ to the desired thickness.

\section{Specimen Design and Preparation}

Several scanning electron microscope (SEM) digital images were produced along with corresponding elemental maps using an X-ray mapping procedure. Figure 1 shows the initial state of the composite. In this figure, the big black regions are the $\mathrm{SiC}$ particles, which are randomly distributed inside the matrix. The particle aspect ratio $\left(\alpha=D_{\max } / D_{\min }, D_{\max }\right.$ and $D_{\min }$ are the maximum and minimum diameters of the particles, respectively) was measured from these images as around 2; and the volume fraction ( $\phi=V_{\text {particle }} / V_{\text {total }}, V_{\text {particle }}$ and $V_{\text {total }}$ are the volumes of the total particles and the whole material domain, respectively) was verified within a range of $17.4-22.9 \%$ with the average value of $20.4 \%$. The alignment preference of the particles along the rolling direction (the vertical direction in Figure 1)

(a)

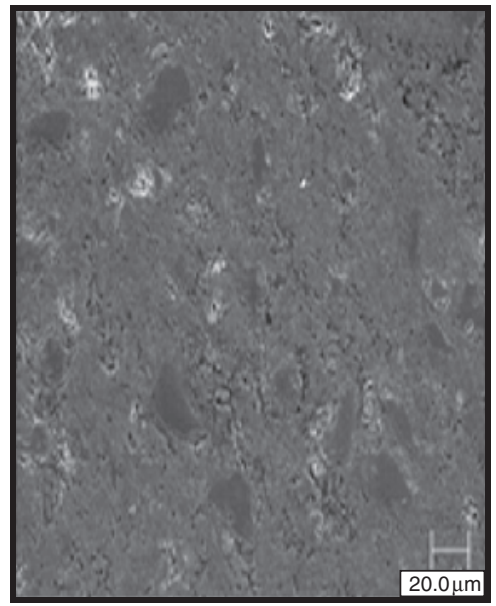

(b)

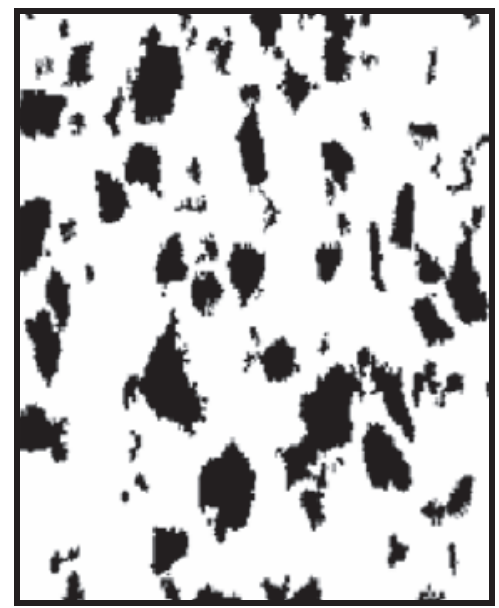

Figure 1. (a) SEM digital images of the initial state of the SiCp/Al composite; and (b) the corresponding X-ray maps (the vertical direction is the rolling direction). 


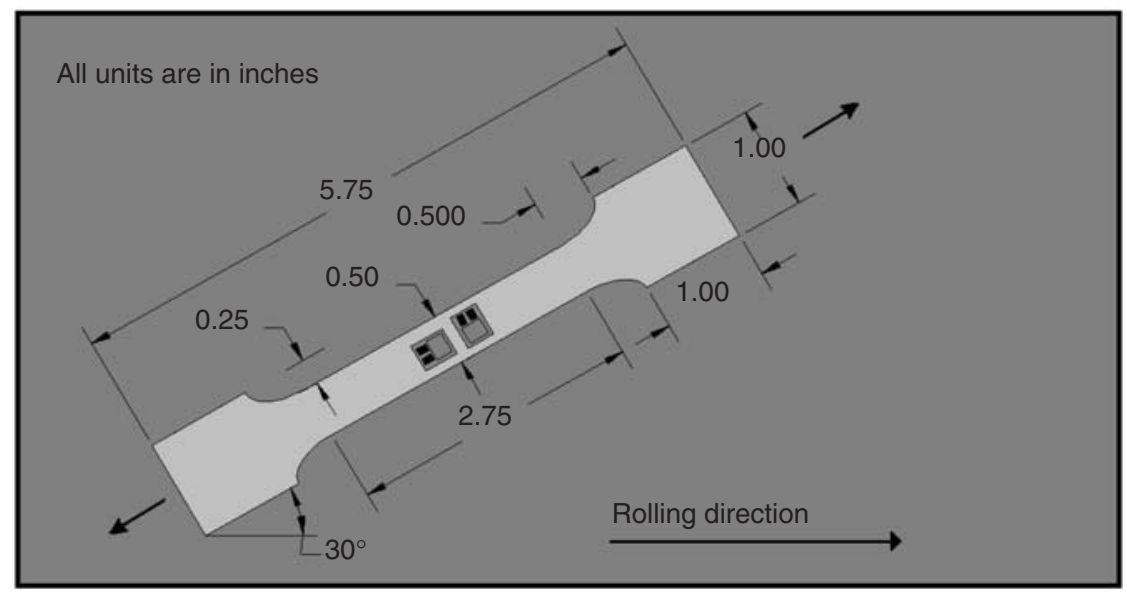

Figure 2. Specimen geometry, orientation angle, and the arrangement of strain gauges.

can be observed clearly, which is caused by the mill pressure during the hot rolling process.

The specimens were cut at various angles $\left(0^{\circ}, 30^{\circ}, 45^{\circ}, 75^{\circ}\right.$, and $\left.90^{\circ}\right)$ to the rolling direction from the composite and matrix-only sheets as exemplified in Figure 2. Two sets of composite specimens with various thicknesses (1.5 and $0.75 \mathrm{~mm}$ ) were used in the uniaxial tension tests while another set of matrix-only A359 specimens (thickness is $3.0 \mathrm{~mm}$ ) was adopted for comparison purpose.

The specimens were divided into two sets for both composite and matrixonly materials. One set remained as receiving condition (as-rolled) while the other set of the specimens went through a heat treatment process (T6) recommended by the manufactory and used by other researchers for similar materials (Lin et al., 1993). These specimens were solutionized at $532^{\circ} \mathrm{C}$ $\left(990^{\circ} \mathrm{F}\right)$ for $30 \mathrm{~min}$, quenched in cold water followed by an aging process at $154^{\circ} \mathrm{C}\left(310^{\circ} \mathrm{F}\right)$ for $5 \mathrm{~h}$. Special care was taken to avoid specimen warping or cracking during the water bath quenching; and no visible damage was detected among the specimens after the heat-treatment process. After specimen preparation, we had 65 samples within the following categories:

- Composite Specimens

(a) $15 \times 1.5 \mathrm{~mm}$ thick in a heat-treated condition

(b) $15 \times 0.75 \mathrm{~mm}$ thick in a heat-treated condition

(c) $15 \times 0.75 \mathrm{~mm}$ thick in an as-rolled condition 


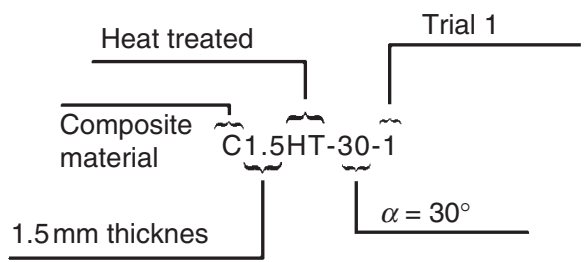

Figure 3. Nomenclature of the specimens.

- Matrix-Only Specimens

(a) $10 \times 3.0 \mathrm{~mm}$ thick in a heat-treated condition

(b) $10 \times 3.0 \mathrm{~mm}$ thick in an as-rolled condition

The following nomenclature illustrated in Figure 3 was designed and adopted to efficiently label each individual specimen removed from the composite sheets. The first letter signifies composite (C) or matrix-only material (M). The first 2-3 digit numbers refer to the thickness of the specimen $(1.5,0.75$, and 3.0). The two letters following the first numbers represent whether the sample underwent the aforementioned heat treatment (HT) or not (AR). The Second set of numbers signifies the orientation angle $(0,30,45,70$, and 90$)$. The final single digit number refers to the trial number.

To measure the axial and transversal strains, two strain gauges (CEA13-125UW-350, Measurements Group, Inc.) were attached to each specimen in both the axial and transverse direction (Figure 2). All the specimens were subjected to uniaxial tension tests using a universal testing machine, and the strain-stress points were recorded to perform the further analysis.

\section{EXPERIMENTAL RESULTS AND DISCUSSION}

\section{Typical Results for Individual Samples}

Figure 4(a) shows a typical stress-strain $(\sigma-\varepsilon)$ curve plotted based on the experiments. In the experimental investigations of anisotropic sheet metals, the definition of yield stress can dramatically alter many results of interest. For the present work, two definitions of yield stress are used: (1) the stress at a $0.2 \%$ plastic strain offset denoted by $\sigma_{y-0.2}$, and (2) the stress at the proportional limit denoted by $\sigma_{y-P L}$. On plotting the required linear translations upon the stress-strain curves, both yield stress definitions can be viewed graphically in Figure 4(a). The linear elastic limit is defined as the point where the linear elastic strain ends and the stress-strain curve 

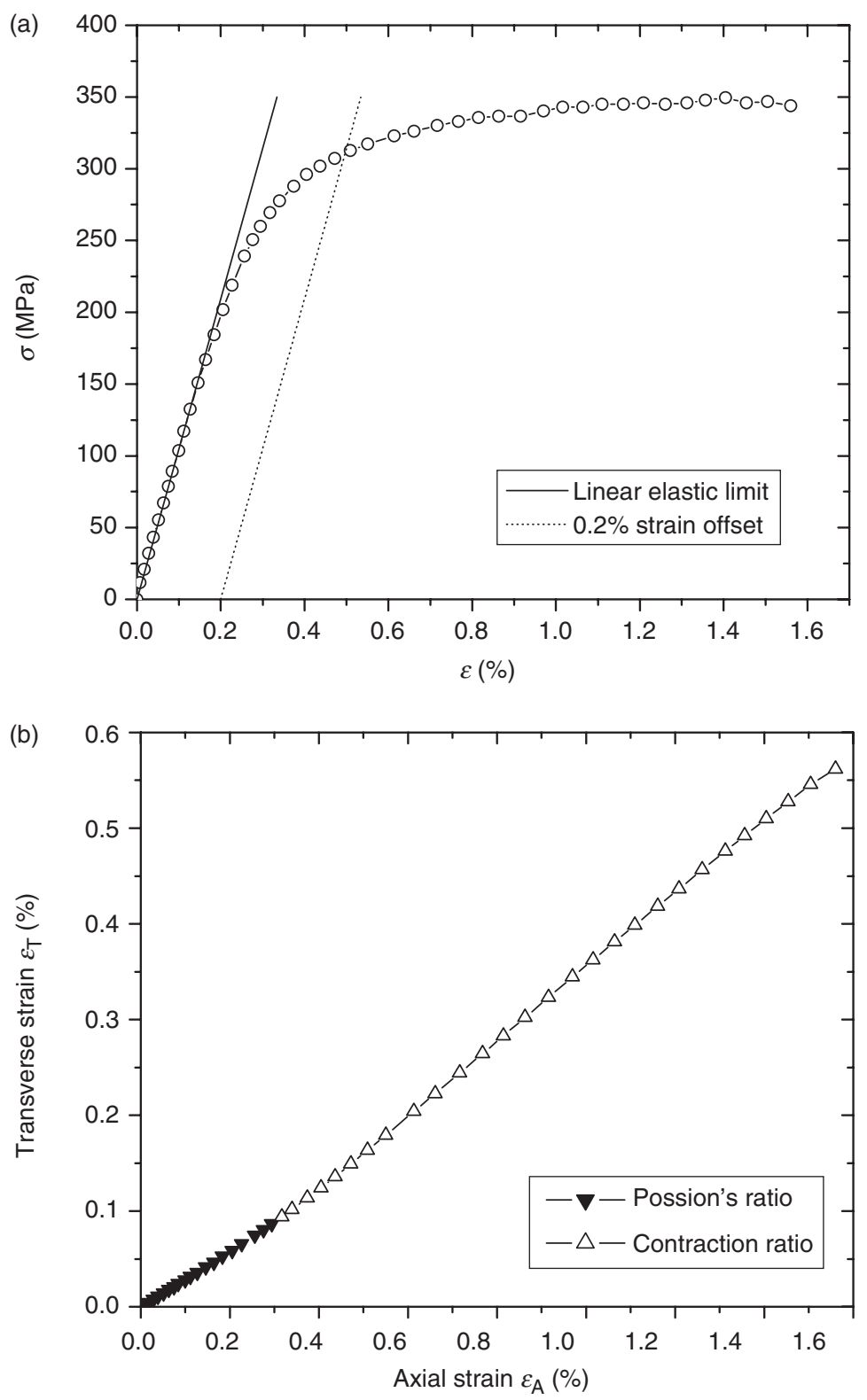

Figure 4. (a) A typical stress-strain curve; and (b) typical strain ratios. 
becomes nonlinear. This is calculated by determining the point where a specific variation develops between the slope governing the elastic region and the continuous stress-strain curve. Because of the difficulty involved in determining the exact point where the variation deviates from zero, a proof strain of $5 \mu \mathrm{m}$ similar to the one specified by Phillips et al. (1972) was used.

Figure 4(b) shows the transverse strain versus the axial strain separated into the elastic and plastic portions. From this plot, two interesting parameters can be determined and compared: Poisson's ratio (v) and the contraction ratio $(\gamma)$ each of which is the slope of the linear regression within the respective regions. As for a uniaxial tension test, these two ratios are defined as follows.

$$
\begin{aligned}
& v=-\frac{\varepsilon_{T}}{\varepsilon_{A}} \quad \text { within the elastic region } \\
& \gamma=-\frac{\varepsilon_{T}}{\varepsilon_{A}} \quad \text { within the plastic region }
\end{aligned}
$$

where $\varepsilon_{A}$ and $\varepsilon_{T}$ are the axial and transversal strains, respectively. From Figure 4(b), the transition from the elastic to the plastic region is clearly visible as the change in slope. Figure 4(b) clearly shows that like the Poisson's ratio, the contraction ratio is a constant for the complete plastic region. The fact that $\gamma$ is greater than $v$ illustrates that, due to an axial loading, more transverse strain is induced in plastic region than in elastic region.

\section{Results and Discussion}

The experimental results are shown in Tables 1-5. Overall speaking, the results for the composite materials have larger deviations than that for the matrix-only materials, demonstrating that the existence of the

Table 1. Experimental results for heat-treated $1.5 \mathrm{~mm}$ composite specimens.

\begin{tabular}{ccccccc}
\hline $\begin{array}{l}\text { Orientation } \\
\text { angle }\end{array}$ & $\boldsymbol{E}(\mathrm{GPa})$ & $\boldsymbol{v}$ & $\gamma$ & $\begin{array}{c}\sigma_{y-P L} \\
(\mathrm{MPa})\end{array}$ & $\begin{array}{c}\sigma_{y-0.2} \\
(\mathrm{MPa})\end{array}$ & $\boldsymbol{\sigma}_{\boldsymbol{u}}(\mathrm{MPa})$ \\
\hline $0^{\circ}$ & $104.4 \pm 13.9$ & $0.30 \pm 0.03$ & $0.37 \pm 0.02$ & $217.6 \pm 17.0$ & $323.9 \pm 6.6$ & $381.7 \pm 5.8$ \\
$30^{\circ}$ & $102.2 \pm 4.7$ & $0.29 \pm 0.01$ & $0.36 \pm 0.01$ & $199.0 \pm 7.3$ & $311.8 \pm 4.6$ & $379.7 \pm 5.5$ \\
$45^{\circ}$ & $100.9 \pm 6.9$ & $0.28 \pm 0.00$ & $0.37 \pm 0.03$ & $213.8 \pm 8.6$ & $314.1 \pm 3.7$ & $374.7 \pm 2.3$ \\
$75^{\circ}$ & $103.5 \pm 5.9$ & $0.27 \pm 0.02$ & $0.36 \pm 0.00$ & $193.0 \pm 3.0$ & $308.1 \pm 0.9$ & $366.7 \pm 1.2$ \\
$90^{\circ}$ & $94.4 \pm 9.8$ & $0.24 \pm 0.03$ & $0.34 \pm 0.03$ & $220.3 \pm 11.1$ & $306.4 \pm 1.6$ & $365.5 \pm 2.3$ \\
\hline
\end{tabular}


Table 2. Experimental results for heat-treated $0.75 \mathrm{~mm}$ composite specimens.

\begin{tabular}{ccccccc}
\hline $\begin{array}{l}\text { Orientation } \\
\text { angle }\end{array}$ & $\boldsymbol{E}(\mathrm{GPa})$ & $\boldsymbol{v}$ & $\boldsymbol{\gamma}$ & \multicolumn{1}{c}{$\sigma_{y-P L}(\mathrm{MPa})$} & $\sigma_{\boldsymbol{y}-\mathbf{0 . 2}}(\mathrm{MPa})$ & $\sigma_{u}(\mathrm{MPa})$ \\
\hline $0^{\circ}$ & $104.9 \pm 0.1$ & $0.27 \pm 0.01$ & $0.39 \pm 0.01$ & $180.0 \pm 12.3$ & $311.8 \pm 1.1$ & $369.2 \pm 0.5$ \\
$30^{\circ}$ & $103.5 \pm 6.1$ & $0.29 \pm 0.01$ & $0.37 \pm 0.01$ & $199.1 \pm 9.7$ & $313.1 \pm 0.9$ & $369.7 \pm 2.8$ \\
$45^{\circ}$ & $109.4 \pm 3.5$ & $0.28 \pm 0.03$ & $0.37 \pm 0.01$ & $207.4 \pm 10.0$ & $318.6 \pm 4.4$ & $371.5 \pm 2.3$ \\
$75^{\circ}$ & $90.8 \pm 3.4$ & $0.27 \pm 0.01$ & $0.38 \pm 0.01$ & $223.1 \pm 7.2$ & $316.7 \pm 2.7$ & $370.7 \pm 2.7$ \\
$90^{\circ}$ & $91.7 \pm 4.5$ & $0.30 \pm 0.01$ & $0.39 \pm 0.00$ & $217.5 \pm 13.6$ & $310.5 \pm 2.8$ & $360.1 \pm 2.3$ \\
\hline
\end{tabular}

Table 3. Experimental results for as-rolled $0.75 \mathrm{~mm}$ composite specimens.

\begin{tabular}{ccccccc}
\hline $\begin{array}{l}\text { Orientation } \\
\text { angle }\end{array}$ & $E(\mathrm{GPa})$ & $\boldsymbol{v}$ & $\gamma$ & $\sigma_{y-P L}(\mathrm{MPa})$ & $\boldsymbol{\sigma}_{\boldsymbol{y}-\mathbf{0 . 2}}(\mathrm{MPa})$ & $\boldsymbol{\sigma}_{u}(\mathrm{MPa})$ \\
\hline $0^{\circ}$ & $107.3 \pm 3.7$ & $0.29 \pm 0.01$ & $0.45 \pm 0.01$ & $108.3 \pm 5.7$ & $194.0 \pm 1.3$ & $226.0 \pm 2.5$ \\
$30^{\circ}$ & $104.3 \pm 4.6$ & $0.29 \pm 0.00$ & $0.43 \pm 0.00$ & $116.0 \pm 11.3$ & $196.4 \pm 2.3$ & $229.1 \pm 0.2$ \\
$45^{\circ}$ & $110.0 \pm 1.9$ & $0.29 \pm 0.03$ & $0.38 \pm 0.01$ & $117.3 \pm 15.2$ & $199.4 \pm 2.3$ & $227.1 \pm 0.9$ \\
$75^{\circ}$ & $105.2 \pm 5.8$ & $0.26 \pm 0.01$ & $0.37 \pm 0.01$ & $126.1 \pm 13.9$ & $200.8 \pm 1.1$ & $224.8 \pm 0.9$ \\
$90^{\circ}$ & $94.3 \pm 2.0$ & $0.27 \pm 0.02$ & $0.36 \pm 0.02$ & $140.6 \pm 9.5$ & $198.0 \pm 4.9$ & $221.4 \pm 0.7$ \\
\hline
\end{tabular}

Table 4. Experimental results for heat-treated $3.0 \mathrm{~mm}$ matrix-only specimens.

\begin{tabular}{cccccc}
\hline $\begin{array}{l}\text { Orientation } \\
\text { angle }\end{array}$ & $E(\mathrm{GPa})$ & $v$ & $\gamma$ & $\sigma_{y-P L}(\mathrm{MPa})$ & $\sigma_{y-\mathbf{0 . 2}}(\mathrm{MPa})$ \\
\hline $0^{\circ}$ & $77.0 \pm 0.1$ & $0.30 \pm 0.00$ & $0.34 \pm 0.01$ & $177.4 \pm 1.5$ & $283.7 \pm 2.9$ \\
$30^{\circ}$ & $78.9 \pm 1.6$ & $0.32 \pm 0.01$ & $0.39 \pm 0.00$ & $176.2 \pm 4.0$ & $289.5 \pm 3.0$ \\
$45^{\circ}$ & $78.2 \pm 0.3$ & $0.31 \pm 0.00$ & $0.36 \pm 0.01$ & $190.8 \pm 12.4$ & $286.9 \pm 2.3$ \\
${ }^{*} 75^{\circ}$ & 80.9 & 0.33 & 0.37 & 186.4 & 291.8 \\
$90^{\circ}$ & $78.3 \pm 3.7$ & $0.31 \pm 0.00$ & $0.42 \pm 0.01$ & $196.1 \pm 19.1$ & $293.6 \pm 0.9$ \\
\hline
\end{tabular}

*Only one specimen survived.

Table 5. Experimental results for as-rolled $3.0 \mathrm{~mm}$ matrix-only specimens.

\begin{tabular}{cccccc}
\hline $\begin{array}{l}\text { Orientation } \\
\text { angle }\end{array}$ & $E(\mathrm{GPa})$ & $\boldsymbol{v}$ & $\gamma$ & $\sigma_{y-P L}(\mathrm{MPa})$ & $\sigma_{y-0.2}(\mathrm{MPa})$ \\
\hline $0^{\circ}$ & $76.4 \pm 1.0$ & $0.31 \pm 0.00$ & $0.37 \pm 0.01$ & $67.0 \pm 0.4$ & $131.0 \pm 0.4$ \\
$30^{\circ}$ & $75.0 \pm 0.9$ & $0.29 \pm 0.01$ & $0.38 \pm 0.01$ & $67.1 \pm 2.1$ & $124.2 \pm 1.3$ \\
$45^{\circ}$ & $71.7 \pm 1.8$ & $0.32 \pm 0.00$ & $0.38 \pm 0.00$ & $74.7 \pm 0.6$ & $126.1 \pm 1.0$ \\
$75^{\circ}$ & $75.5 \pm 0.4$ & $0.30 \pm 0.01$ & $0.33 \pm 0.01$ & $70.9 \pm 4.6$ & $124.8 \pm 1.6$ \\
$90^{\circ}$ & $79.3 \pm 2.7$ & $0.34 \pm 0.01$ & $0.28 \pm 0.00$ & $62.2 \pm 1.0$ & $125.3 \pm 1.4$ \\
\hline
\end{tabular}




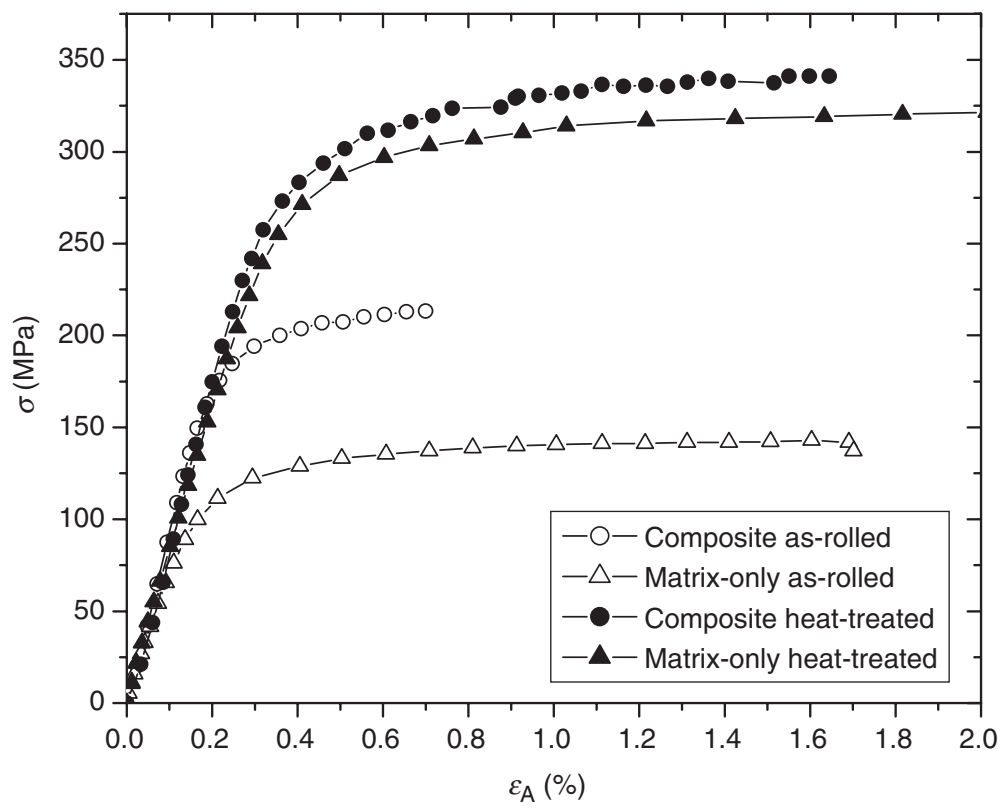

Figure 5. Stress-strain curves for all four types of specimens for an orientation angle $90^{\circ}$.

microstructure of composites introduces more uncertainty, which leads to more scattering on the experiments.

Figure 5 displays characteristic stress-strain curves for the four major specimen types; composite heat-treated, composite as-rolled, matrix-only heat treated, and matrix-only as-rolled for an orientation angle of $90^{\circ}$. As expected, heat-treated specimens display superior strength for both composite and matrix-only specimens. An interesting observation is the relative change resulting from the processing condition. The addition of $\mathrm{SiC}$ particles increases the strength of the specimens in the as-rolled condition more dramatically than their counterparts in the heat-treated condition. The heat treatment procedure seems to affect the strength of the matrix-only specimens more dramatically than the composite specimens do. To investigate these observations further with respect to orientation angle, the corresponding yield stresses and elastic modulus (Young's modulus) are averaged and plotted for comparison in Figure 6.

From Figure 6(a) and (c), anisotropy with respect to the yield stress defined by the proportional limit and the elastic modulus of both composite and matrix-only specimens becomes apparent although a direct relationship is unclear. This is not the case for the yield stress defined by a $0.02 \%$ 

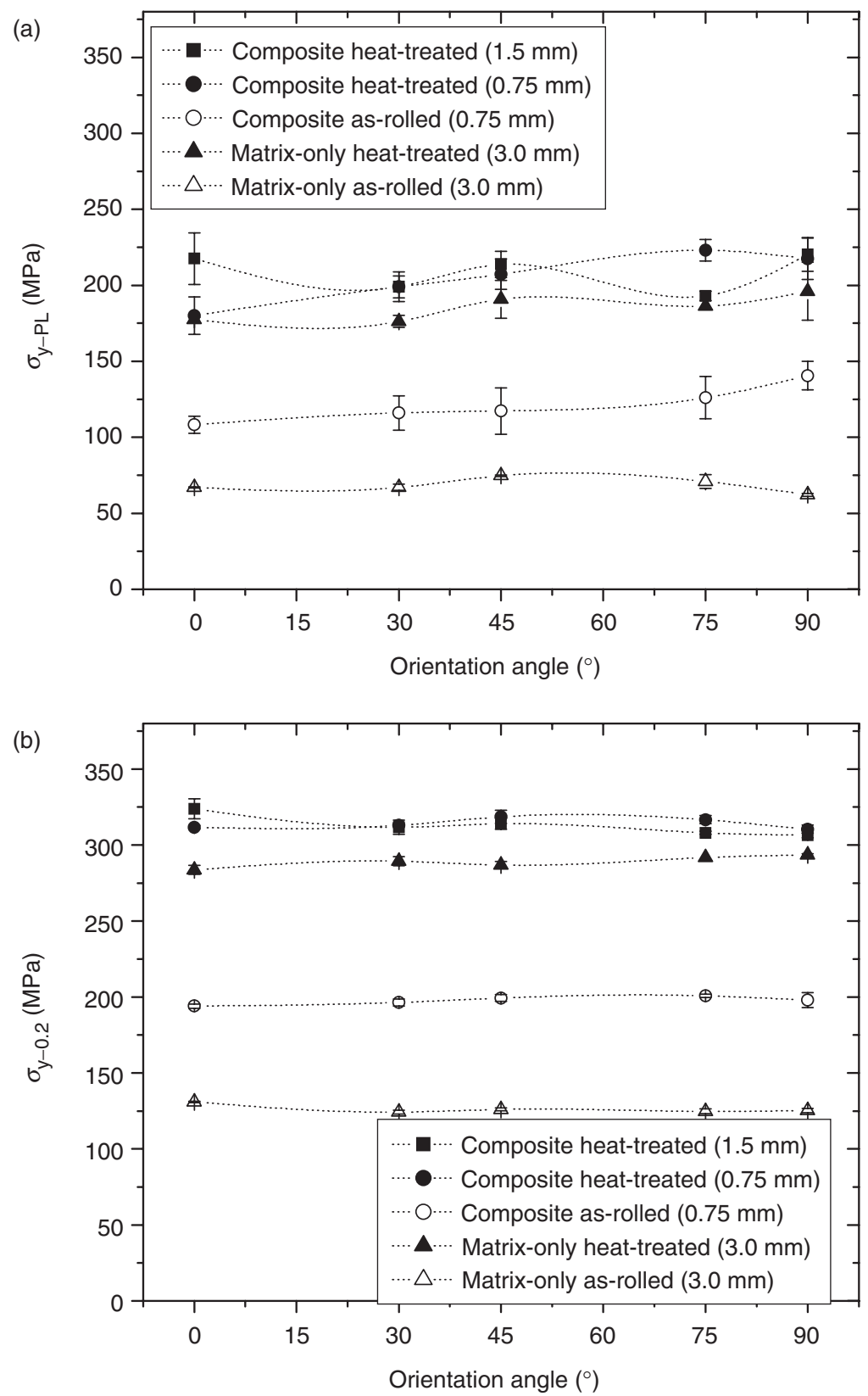

Figure 6. Experimental results verse the orientation angles; (a) yield stress at the proportional limit; (b) yield stress at a $0.2 \%$ strain offset; and (c) elastic modulus. 


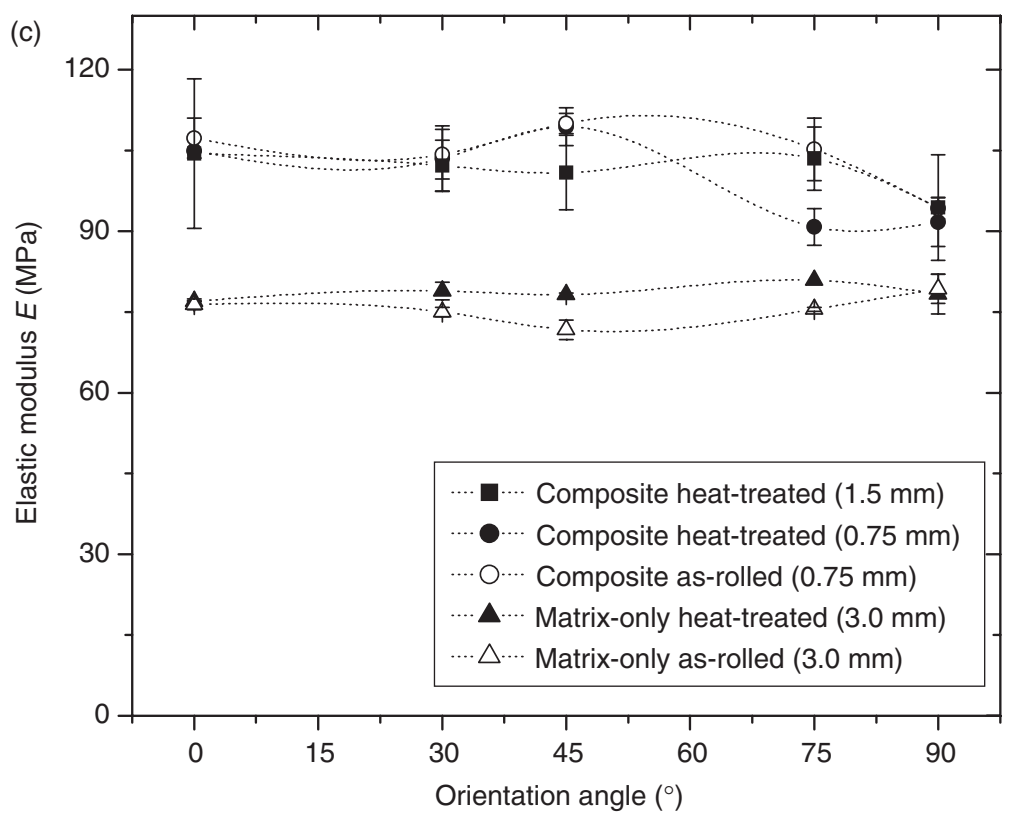

Figure 6. Continued.

strain offset, Figure 6(b), in which data seems nearly independent of the orientation angle. It can be concluded that when investigating the anisotropic behavior of composite sheet metal, the definition of yield stress is quite important.

It is the primary goal of aluminum PRMMCs to maintain the aluminum matrix's light weight while substantially increasing strength and stiffness. From Figure 5, one can see a small increase in strength between the heattreated composite specimens and the matrix-only ones. When inspecting the data with respect to orientation angle, the same conclusion is reached. In the heat-treated specimens, a consistent $15 \%$ increase in averaged $\sigma_{y-P L}$ is displayed independently of the orientation angle and, it is interesting to note, that the addition of $\mathrm{SiC}$ particles has apparently no effect on the specific anisotropic behavior with respect to $\sigma_{y-P L}$. However, a more dramatic increase in the elastic modulus is enthusiastically observed and unlike $\sigma_{y-P L}$, the increase in Young's modulus is dependent on the orientation angle. For example, the greatest increase of over $40 \%$ is seen for the $45^{\circ}$ specimens, while the smallest, yet still impressive increase of near $20 \%$, is seen where the orientation angle is $90^{\circ}$. This is a direct cause in the anisotropic behavior with respect to the observed increases in $E$. It is also confirming to discern, that except for expected scatter, there is little noticeable difference in $E$ data 
with respect to thickness or heat treatment. It is of course well known that heat treatment does not affect the elastic modulus; however, the little effect of the thickness change suggests that the specimens were designed efficiently to test the material and not the structure. At this point it was prudent to study the anisotropic behavior of the material in question with respect to plastic flow stress. Because of the plastically induced anisotropy from the hot-rolling procedure, we would also expect some variation among these parameters with respect to the orientation angle.

Again, anisotropic behavior is nearly indistinguishable among stresses beyond the yield stress defined by the proportional limit, although a slightly decreasing trend seems to emerge. However, $\sigma_{y-P L}$ displays an increasing trend with respect to the orientation angle with the strongest $\sigma_{y-P L}$ exhibited by the specimens of $90^{\circ}$ in all specimen type except matrix-only in the as-rolled condition where the direct relationship is unclear. It can be concluded that the overall strength within the plastic region of the present material decreases as the orientation angle increases, while the initial yield stress defined by the proportional limit increases as the orientation angle increases.

Of additional interest is the anisotropic behavior of the present PRMMC with respect to the strain ratios defined in Equations (1) and (2). Figure 7 displays the average strain ratios within the elastic and plastic regions comparatively. In determining $v$, the linear relationship between $\varepsilon_{A}$ and $\varepsilon_{T}$ within the elastic region is expected. However, whether or not $\varepsilon_{A}$ and $\varepsilon_{T}$ are linearly related within the plastic region, is an important question. From many trials, a plot similar to the one seen in Figure 4(b) can be drawn with impressive $R^{2}$ values. For the purpose of the present work, we will assume that a linear relationship between $\varepsilon_{A}$ and $\varepsilon_{T}$ exists within the entire elastic-plastic region. It should be said that the exact point where the characteristic curve goes from linear to nonlinear, which is the same point where the change in slope becomes evident in the $\varepsilon_{A}$ versus $\varepsilon_{T}$ space, is not easily determined and is dependent on the manner in which the researcher analyzes each individual set of data. For consistency among the tested specimens, all data points taken before the proportional limit are used in determining linear properties; i.e., $E$ and $v$, and all data points taken on or after the proportional limit are used in determining the other properties; i.e., $\gamma$. Another assumption, that heat treatment has little or no effect on the strain ratios, can be verified by inspection of Tables $1-5$.

This assumption holds well for $v$ but it is important to note the apparent exceptions for $\gamma$ seen in both the composite and matrix-only materials. Although this unexplained phenomenon may warrant further study, it is not investigated here and the aforementioned assumptions still hold. When investigating Figure 7, the addition of $\mathrm{SiC}$ particles seems to have opposite 

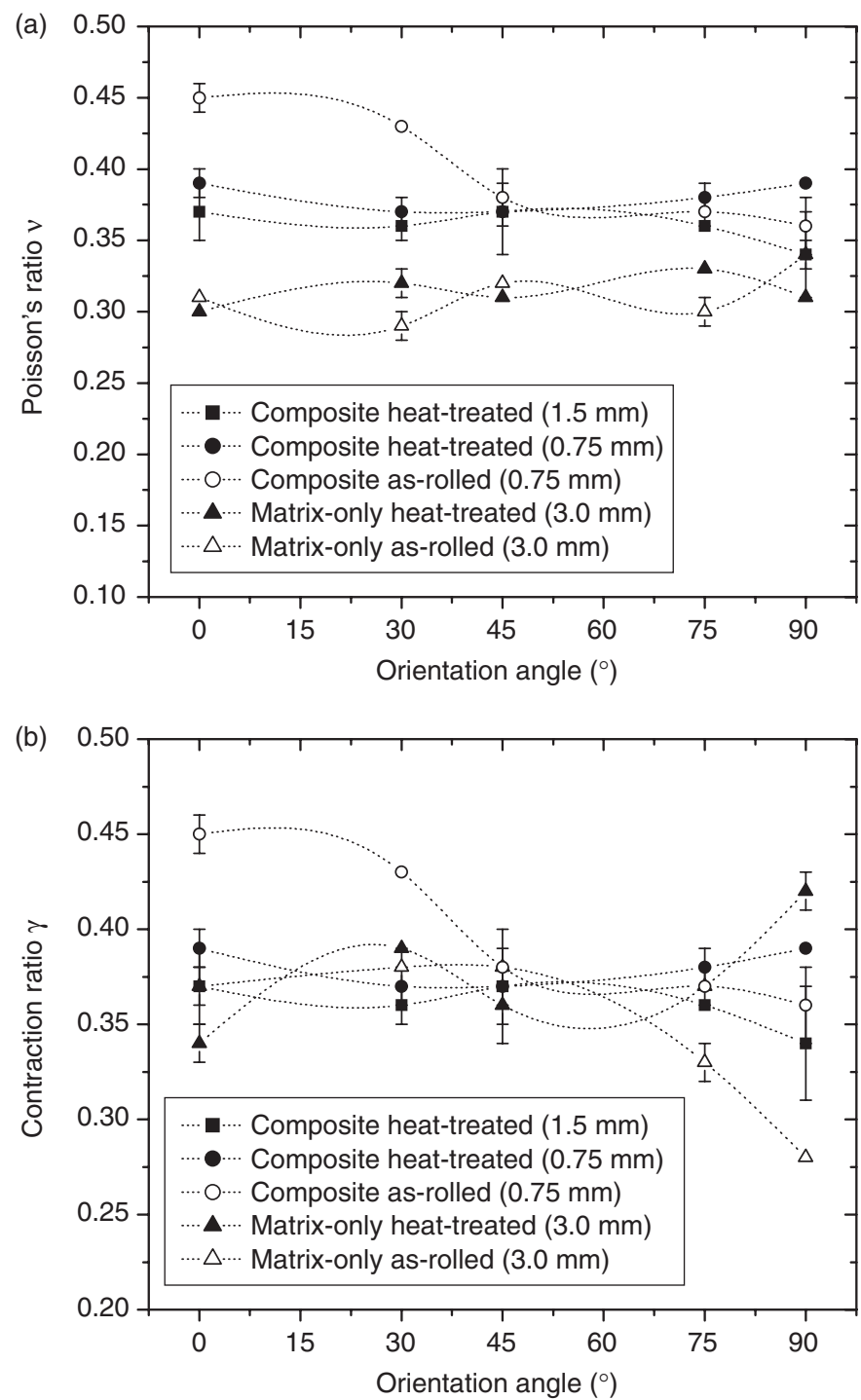

Figure 7. Strain ratios for all specimen types; (a) Poisson's ratio for elastic region; and (b) contraction ratio for plastic region.

affects on each strain ratio. Poisson's ratio is definitely decreased and the amount of decrease seems to be dependent on the orientation angle with higher intensity as the orientation angle increases. The contraction ratio seems to be slightly increased because of the addition of $\mathrm{SiC}$ particles 
although a totally different and unclear trend with respect to the orientation angle exists.

\section{MODELING AND SIMULATION}

\section{Theoretical Modeling}

Modeling and simulation of damage behavior of heterogeneous composite materials is an active research field (e.g., Ju et al., 2006; Voyiadjis and Abu Al-Rub, 2006; Voyiadjis et al., 2007; Dorgan and Voyiadjis, 2006; Abu Al-Rub and Voyiadjis, 2006; Lee and Ju, 2007; Rinaldi et al., 2007; Ricci and Brunig, 2007; Flaceliere et al., 2007). Recently, Sun and co-workers have developed a series of composites elastoplastic/damage models based on micromechanics framework and homogenization procedure (Sun et al., 2003, Sun and Ju, 2004; Liu and Sun, 2004, 2005; Liu et al., 2004, 2005, 2006; Paulino et al., 2006). To explain the observed trends discussed in the previous section, a micromechanical damage model is proposed to predict the effective elastoplastic behavior and damage evolution of metal-matrix composite sheets containing randomly located and unidirectionally aligned spheroidal particles with interfacial debonding based on our previous work. There are two significant changes of the microstructure of composites induced by hot-rolling process. First, particles tend to align in the rolling direction due to pressure introduced by the rolling process (Figure 1); second, interfacial debonding was found on the particle-matrix interface in the rolling direction and these debonding did not appear to heal even after the solution treatment (Lee and Subramanian, 1995).

In the proposed damage model, an equivalent inclusion treatment was adopted. Namely, the debonded isotropic particles were substituted by perfectly bonded particles with equivalent orthotropic properties. The lost of the load-transfer ability in the debonding direction was simulated by the decreased elastic modulus in that direction. If the original isotropic elastic stiffness of the particles can be written as

$$
C_{i j k l}^{(1)}=\lambda^{(1)} \delta_{i j} \delta_{k l}+\mu^{(1)}\left(\delta_{i k} \delta_{j l}+\delta_{i l} \delta_{j k}\right)
$$

where $\lambda^{(1)}$ and $\mu^{(1)}$ are the Lame constants of the particles. Further, the corresponding equivalent orthotropic (anisotropic) stiffness tensor for the debonded particles can be phrased as

$$
C_{i j k l}^{(2)}=\lambda_{I K}^{(2)} \delta_{i j} \delta_{k l}+\mu_{I J}^{(2)}\left(\delta_{i k} \delta_{j l}+\delta_{i l} \delta_{j k}\right)
$$


where

$$
\begin{aligned}
\lambda_{I K}^{(2)} & =\frac{\lambda^{(1)}}{\lambda^{(1)}+\mu^{(1)}}\left(\lambda^{(1)} \beta+\mu^{(1)} \beta_{I} \beta_{K}\right) \\
\mu_{I J}^{(2)} & =\mu^{(1)} \beta_{I} \beta_{J}
\end{aligned}
$$

with

$$
\beta_{I}=\left\{\begin{array}{l}
1, \quad \text { Debonding happens in } I \text {-th direction } \\
0, \quad \text { No debonding happens in } I \text {-th direction }
\end{array}\right.
$$

and

$$
\beta=\beta_{1} \beta_{2} \beta_{3}
$$

In the above equations, Mura's (1987) tensorial indicial notation is followed here, i.e., repeated lower-case indices are summed up from 1 to 3, whereas upper-case indices take on the same numbers as the corresponding lowercase ones but are not summed up.

By a similar ensemble average procedure proposed by Ju and Sun (Ju and Sun, 2001; Sun and Ju, 2001), the overall constitutive relation of the composite can be obtained. The effective stress $\overline{\boldsymbol{\sigma}}$ and effective elastic strain $\overline{\boldsymbol{\varepsilon}}^{e}$ shows a linear relation as

$$
\overline{\boldsymbol{\sigma}}=\overline{\mathbf{C}}: \bar{\varepsilon}^{e}
$$

Here, the effective elastic stiffness of composites $\overline{\mathbf{C}}$ can be determined as (Ju and Chen, 1994)

$$
\overline{\mathbf{C}}=\mathbf{C}^{(0)} \cdot\left[\mathbf{I}+\left(\mathbf{Y}^{-1}-\mathbf{S}\right)^{-1}\right]
$$

with

$$
\mathbf{Y}=\sum_{\eta=1}^{2} \phi^{(\eta)}\left[\mathbf{S}+\left(\mathbf{C}^{(\eta)}-\mathbf{C}^{(0)}\right)^{-1} \cdot \mathbf{C}^{(0)}\right]^{-1}
$$

In the above equations, $\mathbf{C}^{(0)}$ is the elastic stiffness tensor of the matrix, and $\mathbf{C}^{(1)}$ and $\mathbf{C}^{(2)}$ are the isotropic and equivalent orthotropic stiffness tensors for the perfectly bonded and partially debonded particles, respectively. In addition, $\phi^{(1)}$ and $\phi^{(2)}$ are the corresponding 
volume fractions. The fourth-rank interior Eshelby tensor $\mathbf{S}$ can be expressed as (Ju and Sun, 1999)

$$
S_{i j k l}=S_{I K}^{(1)}(0) \delta_{i j} \delta_{k l}+S_{I J}^{(2)}(0)\left(\delta_{i k} \delta_{j l}+\delta_{i l} \delta_{j k}\right)
$$

with

$$
\begin{aligned}
& S_{I K}^{(1)}(\lambda)=-\frac{v_{0}}{2\left(1-v_{0}\right)} J_{I}(\lambda)+\frac{1}{4\left(1-v_{0}\right)}\left[\frac{a_{I}^{2}}{a_{I}^{2}-a_{K}^{2}} J_{I}(\lambda)+\frac{a_{K}^{2}}{a_{K}^{2}-a_{I}^{2}} J_{K}(\lambda)\right] \\
& S_{I J}^{(2)}(\lambda)=-\frac{1}{4}\left[J_{I}(\lambda)+J_{J}(\lambda)\right]+\frac{1}{4\left(1-v_{0}\right)}\left[\frac{a_{I}^{2}}{a_{I}^{2}-a_{J}^{2}} J_{I}(\lambda)+\frac{a_{J}^{2}}{a_{J}^{2}-a_{I}^{2}} J_{J}(\lambda)\right]
\end{aligned}
$$

and

$$
\begin{aligned}
J_{I}(\lambda) & =\int \frac{\rho^{3}(\lambda)}{a_{I}^{2}+\lambda} \mathrm{d} \lambda \rho_{I}(\lambda) \equiv \frac{a_{I}}{\sqrt{a_{I}^{2}+\lambda}} \\
\rho(\lambda) & \equiv\left[\rho_{1}(\lambda) \rho_{2}(\lambda) \rho_{3}(\lambda)\right]^{1 / 3} \\
J_{I}(\lambda) & =\int \frac{\rho^{3}(\lambda)}{a_{I}^{2}+\lambda} \mathrm{d} \lambda
\end{aligned}
$$

Here, $v_{0}$ is Poisson's ratio of the matrix; and $a_{I}(I=1,2,3)$ are the radii of the particle.

The plastic flow of composites is postulated to be associative. The macroscopic plastic strain rate $\dot{\bar{\varepsilon}}^{p}$ for PRMMCs takes the form:

$$
\dot{\bar{\varepsilon}}^{p}=\dot{\lambda} \frac{\partial \bar{F}}{\partial \overline{\boldsymbol{\sigma}}}
$$

where $\dot{\lambda}$ is the plastic consistency parameter. Moreover, $\bar{F}$ is the overall yield function of composites, which can be micromechanically determined as

$$
\bar{F}=\left(1-\phi^{(1)}\right) \sqrt{\overline{\boldsymbol{\sigma}}: \overline{\mathbf{T}}: \overline{\boldsymbol{\sigma}}}-K\left(\bar{e}^{p}\right) \leq 0
$$

Here, $\bar{e}^{p}$ represents the effective equivalent plastic strain, while the simple isotropic hardening function $K\left(\bar{e}^{p}\right)$ is proposed as

$$
K\left(\bar{e}^{p}\right)=\sqrt{\frac{2}{3}}\left[\sigma_{y}+h\left(\bar{e}^{p}\right)^{q}\right]
$$


where $\sigma_{y}$ denotes the initial yield stress of matrix material, $h$ and $q$ signify the linear and exponential isotropic hardening parameters. It is noted that the current model does not take into account the kinematic hardening although the extension should be straightforward. The explicit expression of the fourrank tensor $\overline{\mathbf{T}}$ can be found in Sun et al.'s (2003) paper.

The debonding will increase proportional to the increase of the external tensile loading. To simulate this evolutionary process using statistical approach, Weibull's (1951) probability function is adopted to depict the volume fraction of debonded particles $\phi^{(2)}$ (Zhao and Weng, 1996).

$$
\frac{\phi^{(2)}}{\phi}=1-\exp \left[-\left(\frac{\bar{\sigma}_{11}^{(1)}}{s}\right)\right]^{m}
$$

The total volume fraction $\phi$ is the summation of the volume fractions of perfectly bonded particles $\phi^{(1)}$ and debonded particles $\phi^{(2)}$. The Weibull parameters $s$ and $m$ are connected to average interfacial strength and debonding evolution rate. For example, when an intermediate rate of $m=5$ is selected, $s$ will be determined as $1.09 \sigma_{\text {cri }}$ with $\sigma_{\text {cri }}$ is the critical debonding strength.

It should be noted that all of the above equations are expressed in the principal coordinates (Figure 8). To simulate the experimental results of the samples with various rolling angles, the general tensor transformation rule is applied.

$$
\bar{C}_{i j k l}^{\prime}=l_{i m} l_{j n} l_{k o} l_{l p} \bar{C}_{\text {mnop }}
$$

where $l_{i j}=\mathbf{e}_{i}^{\prime} \cdot \mathbf{e}_{j}$; and $\mathbf{e}_{i}^{\prime}, \mathbf{e}_{j}$ are the base vectors of local and principal Cartesian Coordinate systems, respectively (Figure 8).

\section{Simulation Results}

In the following simulations, the Young's modulus and Poisson's ratio of the $\mathrm{SiC}$ particles are $E_{p}=483 \mathrm{GPa}$ and $v_{p}=0.2$, respectively. The Young's modulus and Poisson's ratio of the matrix are obtained for the experimental results of the matrix-only samples. The aspect ratio of the spheroidal particles is approximated as $\alpha=2$ (Figure 9). The initial debonding due to hot-rolling process is related with several factors, such as reduction ratio, temperature, particles' shape and distribution, etc. In this study, a $20 \%$ of particles are assumed initially debonded from matrix to compromise all of the above factors. Similar to this, the critical debonding strength $\sigma_{\text {cri }}$ is selected as $0.3 \sigma_{y}$. The plastic parameters of the matrix 


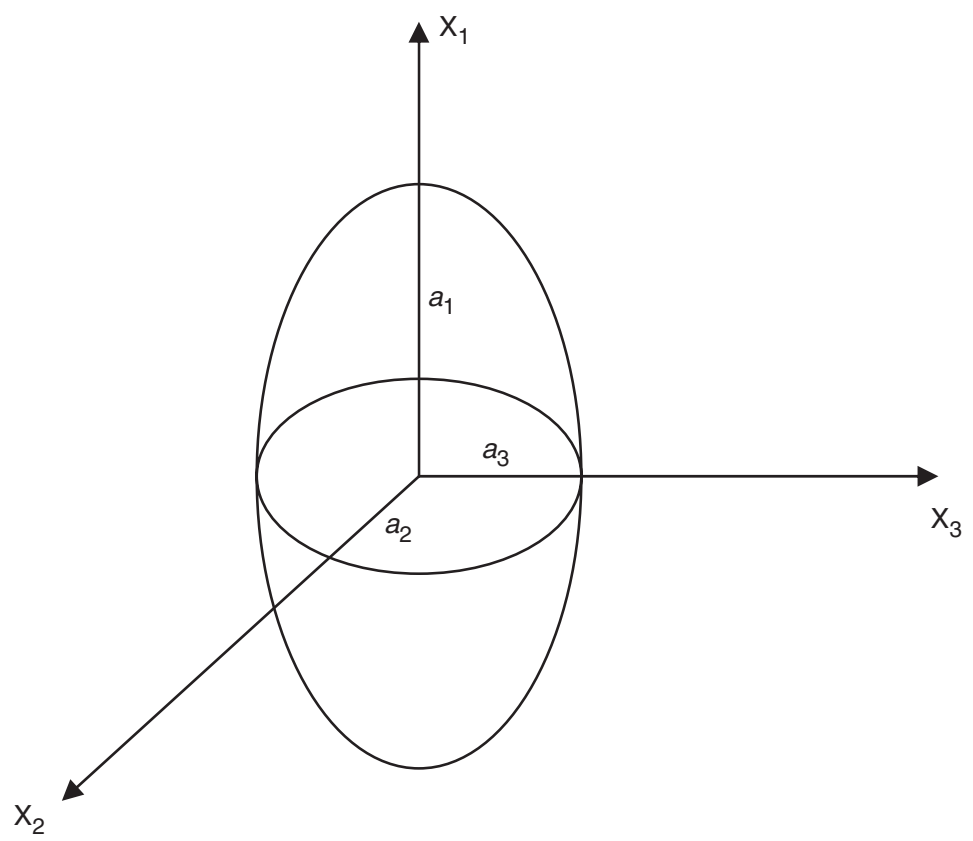

Figure 8. Principal $\left(x_{i}\right)$ and local $\left(x_{i}^{\prime}\right)$ coordinate systems.

$\sigma_{y}, h$, and $q$ are obtained by fitting the experimental results of the matrixonly samples.

Figure 10 shows simulation results of the sample with $0^{\circ}$ orientation angle. It is shown in Figure 10(a) that the theoretical simulation compares well with the experimental data in the entire range except the initial yield region. This discrepancy is probably because in the theoretical model, the effect of thermal residual stresses is ignored. Figure 10(b) shows the simulation of strain ratio. It can be seen that the simulation predicates the strain ratio well for the elastic region. With the increase of the total strain, the predication becomes slightly higher than the experimental data. Figure 11 shows the comparison for the result of $90^{\circ}$ and good agreements are also observed for other orientation angles. Figure 12 shows the simulation of $0.2 \%$ offset yield stress $\sigma_{y-0.2}$ for various orientation angles. In this figure, the simulation is very close to the experimental results. Both experimental results and theoretical simulation indicate that $\sigma_{y-0.2}$ is not much sensitive to the orientation angles. Figure 13 shows the plastic strain corresponding to $350 \mathrm{MPa}$ stress for various orientation angles. It is clearly shown that the plastic strain increase when the orientation angle changes 

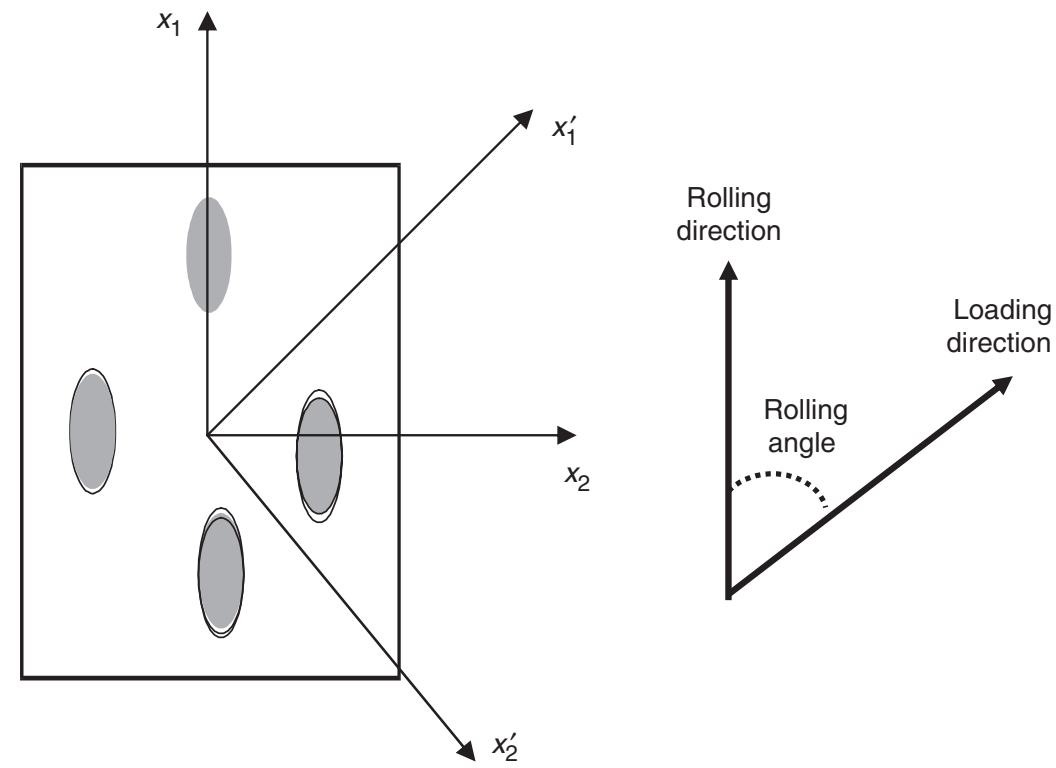

Figure 9. Sketch of a particle (for spheroidal particle $a_{2}=a_{3}$, and the aspect ratio of the particle is defined as $\left.\alpha=a_{1} / a_{2}\right)$.

from $0^{\circ}$ to $90^{\circ}$ and the simulation results is able to catch this trend very well. Both the experimental observation and the simulation results show that the anisotropy of the hot-rolled composite sheet material can be more clearly reflected by the strain hardening instead of the initial yield stress. It is believed that the existence of spheroidal particles reinforces the particlealigned direction much than the transverse direction, which results in more hardening when the uniaxial loading direction is consistent with the particlealigned direction (rolling direction).

$R$-Ratio defined as $R=\mathrm{d} \varepsilon_{w}^{p} / \mathrm{d} \varepsilon_{t}^{p}$ is a widely used parameter representing the normal anisotropy of sheet materials. In the above equation, $\mathrm{d} \varepsilon_{w}^{p}$ and $\mathrm{d} \varepsilon_{t}^{p}$ are the plastic strain increments in the width and thickness directions, respectively. ASTM standards (ASTM, 1996) suggest a more practical definition to obtain $R$-Ratio using uniaxial tension tests. Namely,

$$
R=\frac{\varepsilon_{w}}{\varepsilon_{t}}
$$

Here, $\varepsilon_{w}$ and $\varepsilon_{t}$ are the total strain in width and thickness directions, respectively. For the sheet materials with very thin thickness, to measure the 
(a) $E_{m}=77 \mathrm{GPa}, v_{m}=0.3, E_{p}=483 \mathrm{GPa}, v_{p}=0.2, \alpha=2, \sigma_{c r i}=0.3 \sigma_{y}$ $\sigma_{y}=177 \mathrm{MPa}, h=290 \mathrm{MPa}, q=0.16, \phi^{\text {Total }}=20 \%, \phi^{\text {Damage }}=20 \%$

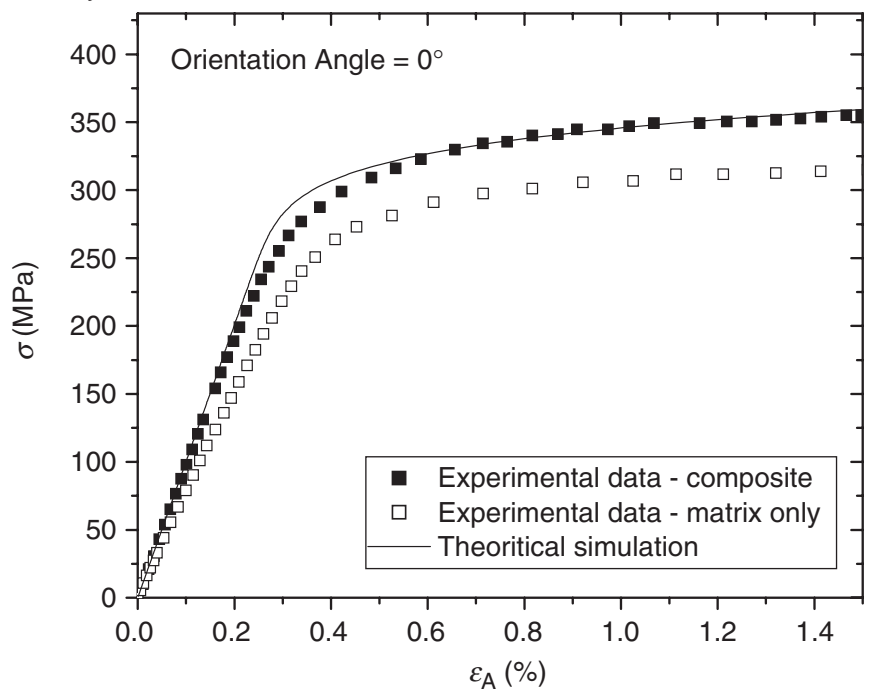

(b) $\quad E_{m}=77 \mathrm{GPa}, v_{m}=0.3, E_{p}=483 \mathrm{GPa}, v_{p}=0.2, \alpha=2, \sigma_{c r i}=0.3 \sigma_{y}$ $\sigma_{y}=177 \mathrm{MPa}, h=290 \mathrm{MPa}, q=0.16, \phi^{\text {Total }}=20 \%, \phi^{\text {Damage }}=20 \%$

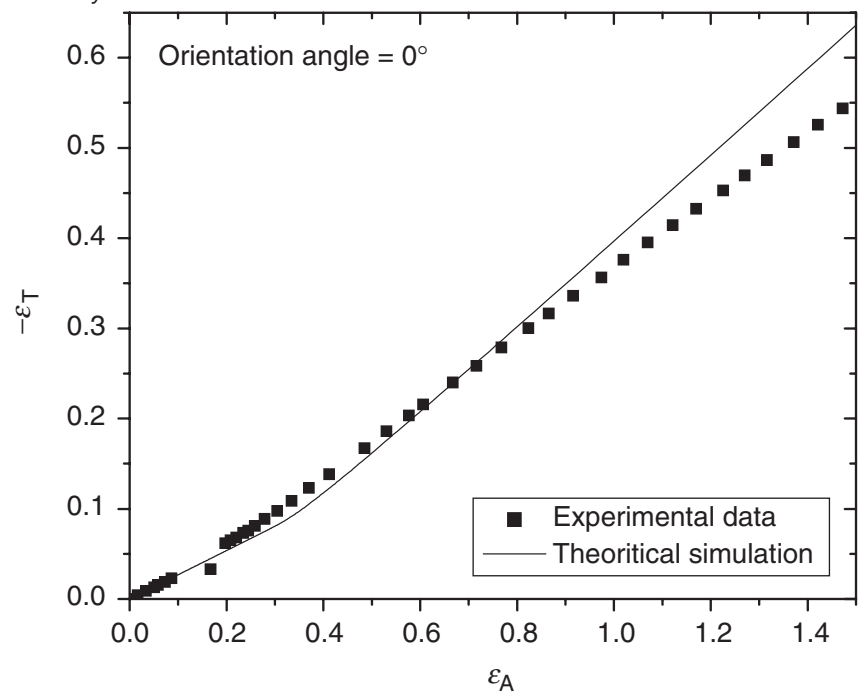

Figure 10. The comparison between theoretical simulation and experimental results (orientation angle $=0^{\circ}$ ); (a) Strain-stress curve; and (b) strain ratio. 
(a) $E_{m}=78 \mathrm{GPa}, v_{m}=0.31, E_{p}=483 \mathrm{GPa}, v_{p}=0.2, \alpha=2, \sigma_{c r i}=0.3 \sigma_{y}$ $\sigma_{y}=196 \mathrm{MPa}, h=310 \mathrm{MPa}, q=0.19, \phi^{\text {Total }}=20 \%, \phi^{\text {Damage }}=20 \%$

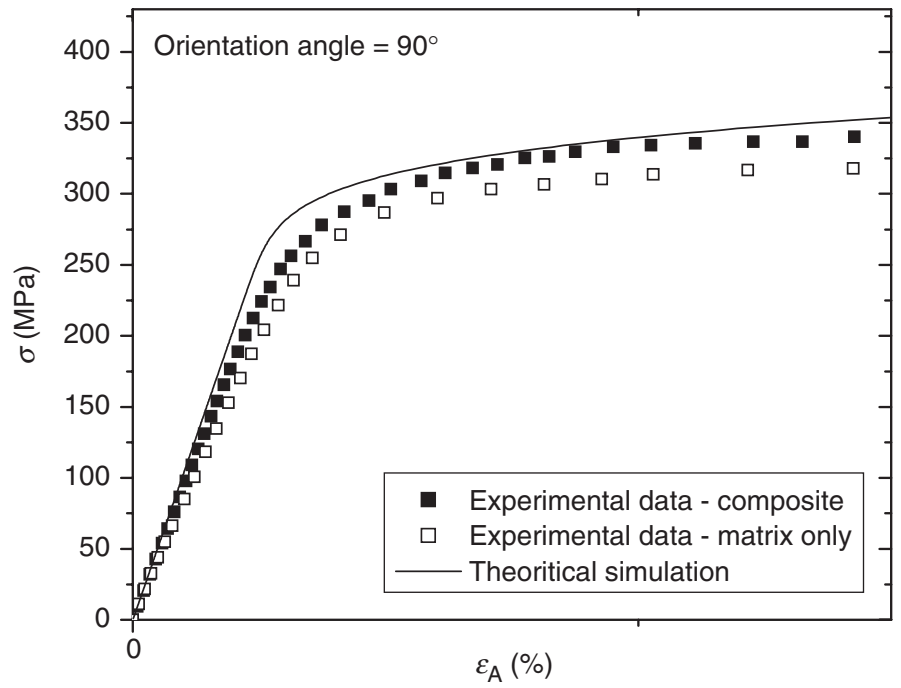

(b) $\quad E_{m}=78 \mathrm{GPa}, v_{m}=0.31, E_{p}=483 \mathrm{GPa}, v_{p}=0.2, \alpha=2, \sigma_{c r i}=0.3 \sigma_{y}$ $\sigma_{y}=196 \mathrm{MPa}, h=310 \mathrm{MPa}, q=0.19, \phi^{\text {Total }}=20 \%, \phi^{\text {Damage }}=20 \%$

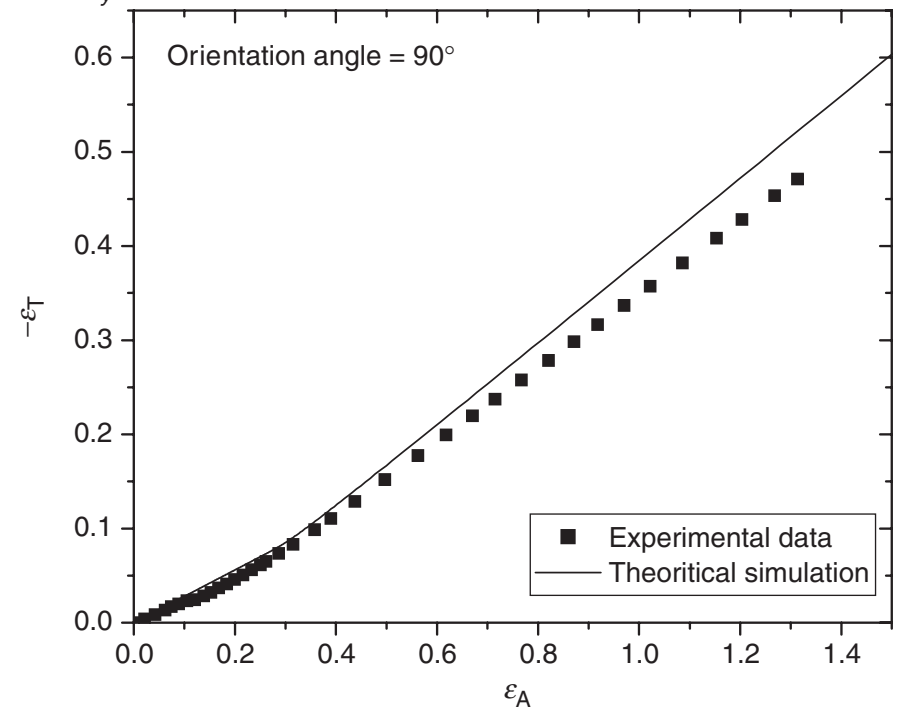

Figure 11. The comparison between theoretical simulation and experimental results (orientation angle $=90^{\circ}$ ); (a) Strain-stress curve; (b) strain ratio. 


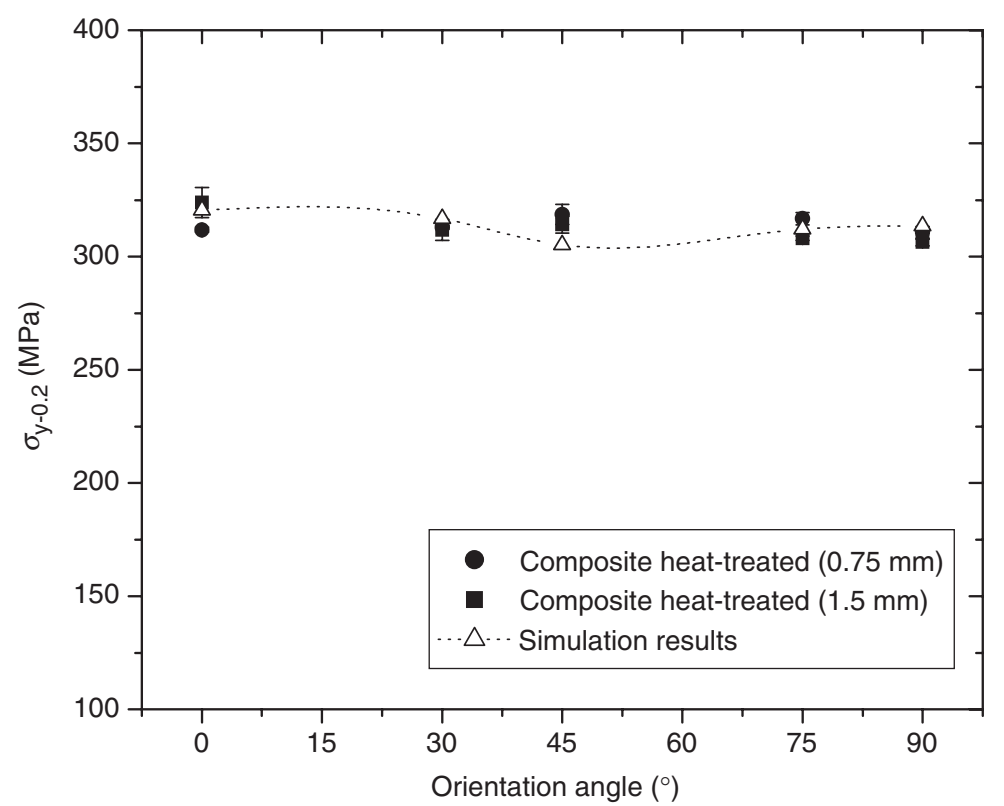

Figure 12. The $0.2 \%$ offset yield stress $\left(\sigma_{y-0.2}\right)$ for various orientation angles.

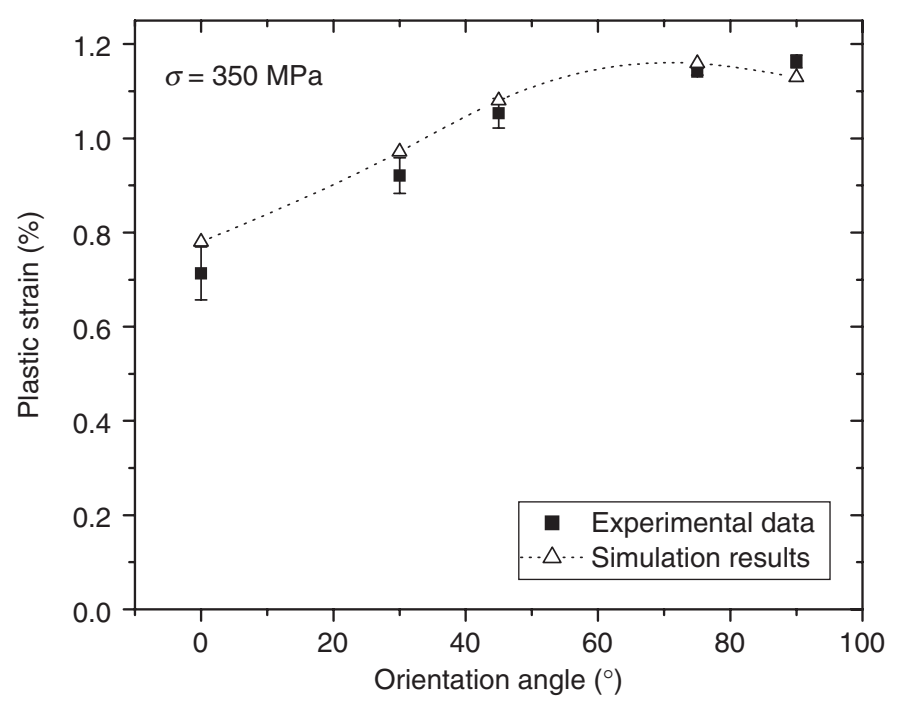

Figure 13. The plastic strain for various orientation angles. 


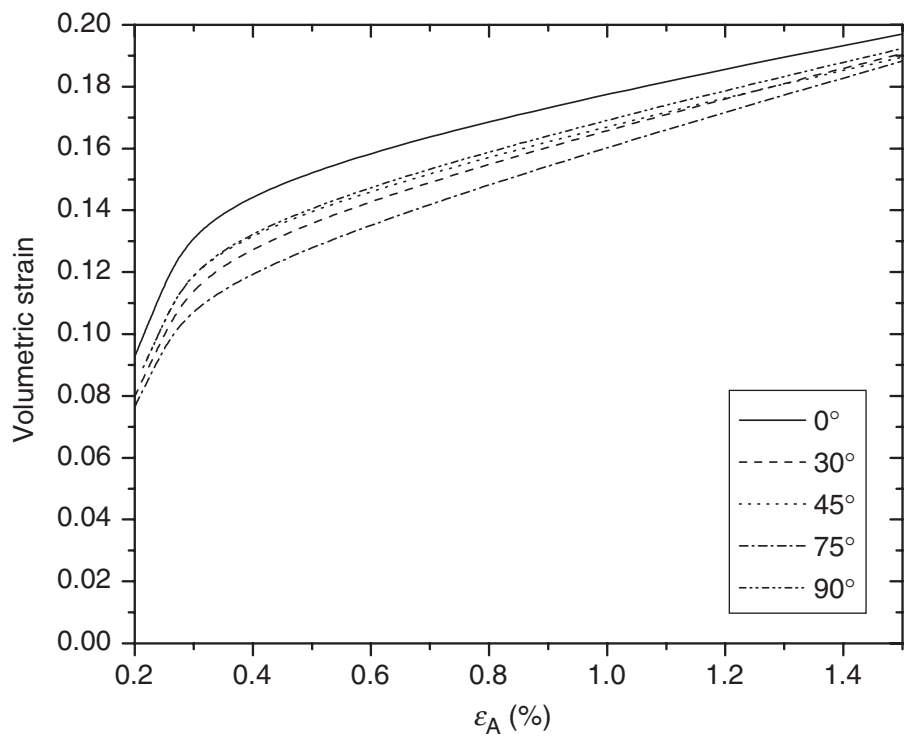

Figure 14. The volumetric strain for various orientation angles.

thickness strain directly is very difficult. Therefore, a constant volumetric strain (incompressibility) is always assumed for metals to calculate the thickness strain by measuring the longitude and transverse strains directly. However, composites are usually compressible and the incompressibility assumption is not longer hold. Therefore, the volumetric strain is computed using the proposed debonding model and is shown in Figure 14 for various orientation angles. It is shown that the relationship between volumetric strain and the axial strain (longitude strain) can be approximated as linear when the total strain is large enough $(>0.4 \%$ in Figure 14). Using the volumetric strain provided in Figure 14 and the experimental data of longitude and transverse strains measured from the experiments, the thickness strain and the $R$-Ratio for various orientation angles are calculated and shown in Figure 15. The proposed model can catch the $R$-Ratio's tend from the experiments with some overestimation, which is possible due to the usage of the volumetric strain obtained from the proposed model as an estimation to calculate the thickness strain for the experiments. A direct measurement of either the thickness strain or the volumetric strain is needed to obtain more accurate $R$-Ratio from experimental approaches. 


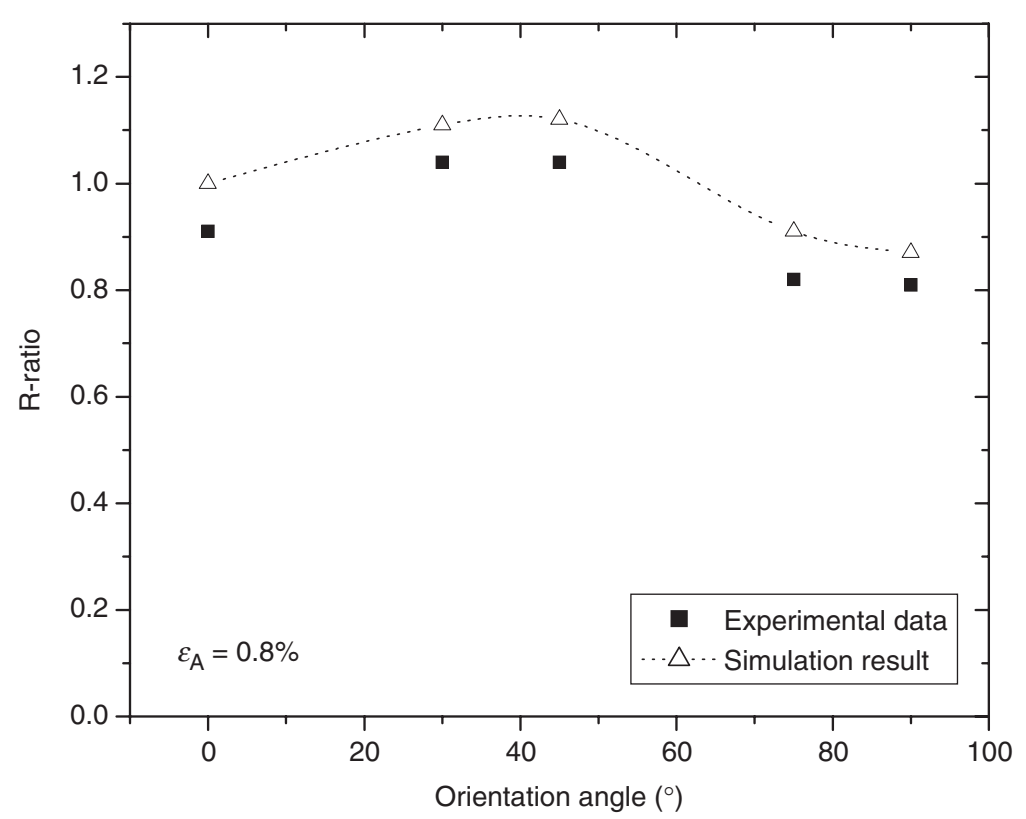

Figure 15. The R-Ratio for various orientation angles.

\section{SUMMARY}

The experimental research was undertaken to investigate the effective strength and elastoplastic constitutive relation of $\mathrm{SiC}$ particle reinforced aluminum matrix composites. Specifically, anisotropic behavior with respect to multiple definitions of yield stress, elastic modulus, multiple strain ratios, and composite processing (heat treated or as-rolled) was studied and discussed in detail. A debonding model is proposed to catch the experimental results and the overall elastoplastic curves are obtained. It is shown from both experiments and theoretical prediction that the anisotropy of the studied composite sheet material is much reflected by the strain hardening than the initial yield stresses for various orientation angles. The $R$-Ratios are obtained using the model-computed volumetric strain.

\section{ACKNOWLEDGEMENTS}

This work was sponsored by the NASA Iowa Space Grant Consortium and the National Science Foundation (CMS-0303955 and CMS-0619328). These supports are gratefully acknowledged. 


\section{REFERENCES}

Abu Al-Rub, R.K. and Voyiadjis, G.J. (2006). A Finite Strain Plastic-damage Model for High Velocity Impact using Combined Viscosity and Gradient Localization Limiters: Part I - Theoretical Formulation, International Journal of Damage Mechanics, 15: 293-334.

ASTM. (1996). Annual Book of ASTM Standards - Metals Test Methods and Analytical Procedures, West Conshohochen, PA.

Cavaliere, P. (2005). Mechanical Properties of Friction stir Processed 2618/Al2O3/20p Metal Matrix Composite, Composites Part A - Applied Science and Manufacturing, 36: $1657-1665$.

Dorgan, R.J. and Voyiadjis, G.Z. (2006). A Mixed Finite Element Implementation of a Gradient-enhanced Coupled Damage-Plasticity Model, International Journal of Damage Mechanics, 15: 201-235.

Euh, K. and Kang, S.B. (2005). Effect of Rolling on the Thermo-Physical Properties of SiCp/Al Composites Fabricated by Plasma Spraying, Materials Science and Engineering A, 395: $47-52$.

Flaceliere, L., Morel, F. and Dragon, A. (2007). Coupling Between Mesoplasticity and Damage in High-cycle Fatigue, Int. J. Damage Mechanics, 16(4): 473-509.

Ju, J.W. and Chen, T.M. (1994). Micromechanics and Effective Moduli of Elastic Composites Containing Randomly Dispersed Ellipsoidal Inhomogeneities, Acta Mech., 103: 103-121.

Ju, J.W. and Sun, L.Z. (1999). A Novel Formulation for Exterior-point Eshelby's Tensor of an Ellipsoidal Inclusion, J. Appl. Mech., 66: 570-574.

Ju, J.W. and Sun, L.Z. (2001). Effective Elastoplastic Behavior of Metal Matrix Composites Containing Randomly Located Aligned Spheroidal Inhomogeneities, Part I: Micromechanics-Based Formulation, Inter. J. Solids Struct., 38: 183-201.

Ju, J.W., Ko, Y.F. and Ruan, H.N. (2006). Effective Elastoplastic Damage Mechanics for Fiber-reinforced Composites with Evolutionary Complete Fiber Debonding, International Journal of Damage Mechanics, 15: 237-265.

Kanetake, N., Kaneko, T. and Choh, T. (1997). Cold Rolling and Mechanical Properties of Particle Reinforced Aluminum Composites, J. Japan Inst. Metals, 61: 1153-1159.

Kourkoulis, S.K. (2002). Quantifying the Plastic Anisotropy for Particulate Metal Matrix Composites, Advanced Composites Letters, 11: 153-163.

Kourkoulis, S.K. and Andrianopoulos, N.P. (2000). Plastically Induced Anisotropy on Metal Matrix Composites, Mechanics of Composite Materials and Structures, 7: 1-17.

Lee, H.K. and Ju, J.W. (2007). A Three-Dimensional Stress Analysis of a Penny-shaped Crack Interacting with a Spherical Inclusion, Int. J. of Damage Mechanics, 16(3): 331-360.

Lee, J.C. and Subramanian, K.N. (1992). Effect of Cold-rolling on the Tensile Properties of $\left(\mathrm{Al}_{2} \mathrm{O}_{3}\right) \mathrm{p} / \mathrm{Al}$ Composites, Mater. Sci. Eng. A, 159: 43-50.

Lee, J.C. and Subramanian, K.N. (1995). The Tensile Properties of Hot-rolled $\left(\mathrm{Al}_{2} \mathrm{O}_{3}\right)_{\mathrm{p}}-\mathrm{Al}$ Composites, Mater. Sci. Eng. A, 196: 71-78.

Lin, J.S., Li, P.X. and Wu, R.J. (1993). Aging Evaluation of Cast Particulate-reinforced SiC/Al (2024) Composites, Scripta Metallurgica et Materialia, 28: 281-286.

Liu, H.T. and Sun, L.Z. (2004). Effects of Thermal Residual Stresses on Effective Elastoplastic Behavior of Metal Matrix Composites, International Journal of Solids and Structures, 41: 2189-2203.

Liu, H.T., Sun, L.Z. and Ju, J.W. (2004). An Interfacial Debonding Model for Particlereinforced Composites, International Journal of Damage Mechanics, 13: 163-185.

Liu, H.T. and Sun, L.Z. (2005). Multiscale Modeling of Elastoplastic Deformation and Strengthening Mechanisms in Aluminum-Based Amorphous Nanocomposites, Acta Materialia, 53: 2693-2701. 
Liu, H.T., Sun, L.Z. and Wu, H.C. (2005). Monte-Carlo Simulation of Particle-cracking Damage Evolution in Metal Matrix Composites, Journal of Engineering Materials and Technology, Transactions of ASME, 127: 318-324.

Liu, H.T., Sun, L.Z. and Ju, J.W. (2006). Elastoplastic Modeling of Progressive Interfacial Debonding for Particle-Reinforced Metal-Matrix Composites, Acta Mech., 181: 1-17.

Miracle, D.B. (2005). Metal Matrix Composites - From Science to Technological Significance, Composites Science and Technology, 65: 2526-2540.

Mura, T. (1987). Micromechanics of Defects in Solids, 2nd edn, Kluwer Academic Publishers.

Phillips, A., Liu, C.S. and Justusson, J.W. (1972). An Experimental Investigation of Yield Surfaces at Elevated Temperatures, Act Mech., 14: 119-146.

Prasad, V.V.B., Bhat, B.V.R., Mahajan, Y.R. and Ramakrishnan, P. (2002). Anisotropy in Structure and Properties of Extruded DRA Composites, Journal of Materials Science Letters, 21: 1019-1021.

Paulino, G.H., Yin, H.M. and Sun, L.Z. (2006). Micromechanics-based Interfacial Debonding Model for Damage of Functionally Graded Materials With Particle Interactions, International Journal of Damage Mechanics, 15: 267-288.

Ricci, S. and Brunig, M. (2007). Numerical Analysis of Nonlocal Anisotropic Continuum Damage, Int. J. of Damage Mechanics, 16(3): 283-300.

Rinaldi, A., Krajcinovic, D. and Mastilovic, S. (2007). Statistical Damage Mechanics and Extreme Value Theory, Int. J. of Damage Mechanics, 16(1): 57-76.

Shamsul, J.B., Hammond, C., Cochrane, R.F. and Shakesheff, A.J. (1998). Influence of Microstructure and Texture on Mechanical Properties Of Aluminium Alloy $2124+5 \%$ SiC Particulate Composites, Materials Science and Technology, 14: 949-958.

Sun, L.Z., Ju, J.W. and Liu, H.T. (2003). Elastoplastic Modeling of Metal Matrix Composites With Evolutionary Particle Debonding, Mechanics of Materials, 35: 559-569.

Sun, L.Z. and Ju, J.W. (2001). Effective Elastoplastic Behavior of Metal Matrix Composites Containing Randomly Located Aligned Spheroidal Inhomogeneities, Part II: Applications, Inter. J. Solids Struct., 38: 203-225.

Sun, L.Z. and Ju, J.W. (2004). Elastoplastic Modeling of Metal Matrix Composites Containing Randomly Located and Oriented Spheroidal Particles, Journal of Applied Mechanics, Transactions of ASME, 71: 774-785.

Voyiadjis, G.Z. and Abu Al-Rub, R.K. (2006). A Finite Strain Plastic-damage Model for High Velocity Impacts using Combined Viscosity and Gradient Localization Limiters: Part II - Numerical Aspects and Simulations, International Journal of Damage Mechanics, 15: $335-373$.

Voyiadjis, G.Z., Kattan, P.I. and Taqieddin, Z.N. (2007). Continuum Approach to Damage Mechanics of Composite Materials with Fabric Tensors, Int. J. of Damage Mechanics, 16(3): 301-330.

Weibull, W. (1951). A Statistical Distribution Function of wide Applicability, J. Appl. Mech., 18: 293-297.

Zhao, Y.H. and Weng, G.J. (1996). Plasticity of a Two-phase Composite with Partially Debonded Inclusions, Inter. J. Plasticity, 12: 781-507. 